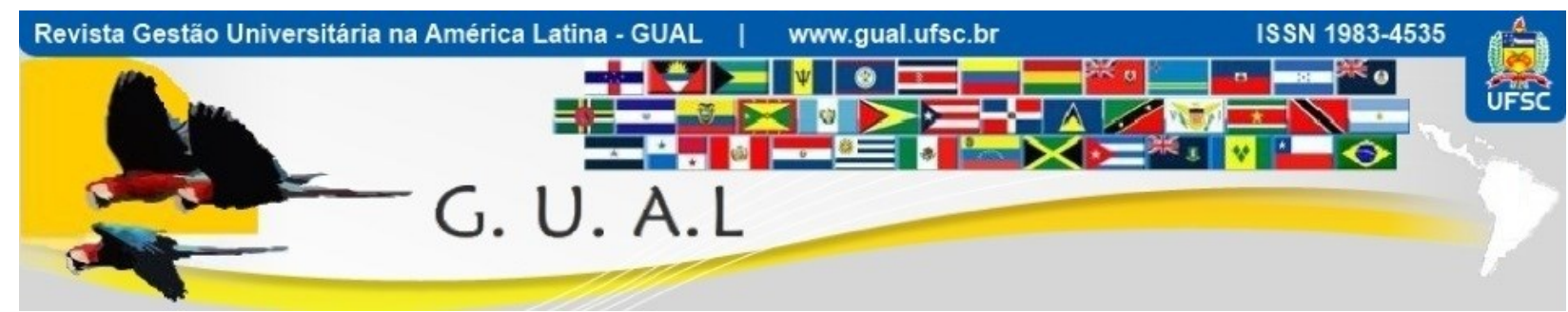

DOI: http://dx.doi.org/10.5007/1983-4535.2018v11n4p256

\title{
INCERTEZA TECNOLÓGICA E INTERAÇÃO ORGANIZACIONAL: IDENTIFICANDO MODELO DE TRANSFERÊNCIA DE TECNOLOGIA ENTRE DUAS INSTITUIÇÕES FEDERAIS DE ENSINO
}

\section{TECHNOLOGICAL UNCERTAINTY AND ORGANIZATIONAL INTERACTION: IDENTIFYING THE MODEL OF TECHNOLOGY TRANSFER BETWEEN TWO FEDERAL TEACHING INSTITUTIONS}

Leandro Aparecido Antunes Steffen, Mestrando Universidade Federal da Grande Dourados - UFGD leandrosteffen@ufgd.edu.br

Renato Moreira Neto, Mestrando Universidade Federal da Grande Dourados - UFGD renatoneto@ufgd.edu.br

Simone Rodrigues Romero, Mestre Universidade Federal da Grande Dourados - UFGD simoneromero@ufgd.edu.br

Jane Corrêa Alves Mendonça, Doutora Universidade Federal da Grande Dourados - UFGD janemendonca@ufgd.edu.br

Erlaine Binotto, Doutora Universidade Federal da Grande Dourados - UFGD erlainebinotto@ufgd.edu.br

Luan Carlos Santos Silva, Doutor

Recebido em 24/novembro/2017 Aprovado em 06/setembro/2018 luancarlos@ufgd.edu.br

Sistema de Avaliação: Double Blind Review Universidade Federal da Grande Dourados - UFGD

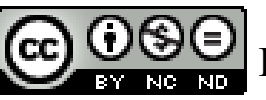

Esta obra está sob uma Licença Creative Commons Atribuição-Uso. 


\begin{abstract}
RESUMO
Este artigo analisa o processo de Transferência de Tecnologia dos sistemas SIG (Sistemas Institucionais Integrados de Gestão) entre a Universidade Federal do Rio Grande do Norte (UFRN) e a Universidade Federal da Grande Dourados (UFGD), a metodologia utilizada consistiu nos conceitos de Incerteza Tecnológica e Interação Organizacional. A análise destes fatores servirá para apontar se a instituição receptora possui as condições necessárias para realizar a transferência, e identificar o melhor modelo de transferência na realidade institucional. Durante a pesquisa, outras instituições que já realizaram, ou estão realizando a transferência do mesmo sistema foram analisadas, afim de identificar quais os modelos de transferência são mais comuns e apontarem os fatores mais relevantes no processo de transferência de tecnologia dos sistemas da UFRN. Como resultados, foi possível identificar a Compra Facilitada e Entrega Colaborativa como sendo os modelos de Transferência de Tecnologia mais evidentes, e que apesar de adaptações que causam impacto no custo final do projeto, as instituições consideram o SIG capaz de gerar valor, caracterizando assim, uma Transferência de Tecnologia eficaz.
\end{abstract}

Palavras-chave: Transferência de Tecnologia. Incerteza Tecnológica. Interação Organizacional. Eficácia.

\begin{abstract}
This paper analyzes the process of Technology Transfer of SIG [Institutional Integrated Management System] between Federal University of Rio Grande do Norte (UFRN) and Federal University of Grande Dourados (UFGD). The methodology we opted was consisted by the concepts of Technological uncertainty and organizational interaction. The analysis of these factors pointed if the receptor institution possess the conditions needed to perform the transfer, and identified the best model of transfer for the institutional reality. During the research, other institutions which already performed or are performing the transfer of such system were assessed in order to identify which models of technology transfer are more common, also in order to point out the most relevant factors in the transfer system from UFRN. As results, it was possible to identify the systems named Compra Facilitada [Easy Purchase] and Entrega Colaborativa [Colaborative Deliverance] as the most evident systems and also, despite the adaptations that caused impacts on the final cost of the projects, the institutions consider SIG system able to generate income, characterizing, thus, an efficient Technology Transfer.
\end{abstract}

Keywords: Technology Transfer. Technological Uncertainty. Organizational Interaction. Efficiency. 


\section{INTRODUÇÃO}

Diversas organizações se utilizam de tecnologias de fontes externas para realizarem suas atividades. A efetiva aquisição e utilização de tecnologias proporcionam resultados para o sucesso. No entanto, adquirir e assimilar novas tecnologias pode ser um processo bastante difícil, levando-se em consideração as inúmeras peculiaridades organizacionais (MONDRAGÓN, DOMÍNGUEZ, FLORES 2013).

Na visão de Stock e Tatikonda (2000), as organizações estão cada vez mais focadas em suas próprias competências. Nestas condições, muitas vezes é preciso buscar tecnologias externas para suprir necessidades latentes (HEINZL et al. 2012).

Esta realidade acaba gerando a necessidade de que as organizações tenham habilidades para transferência de tecnologia, já que menos produtos e tecnologias são gerados internamente. Este know-how colabora para que os processos sejam efetivos e eficientes em tempo e custo (STOCK E TATIKONDA 2000).

Stock e Tatikonda (2008), em seus estudos, criaram uma estrutura capaz de fornecer orientação para seleção das melhores abordagens de gestão para transferência de tecnologia. Como o processo de transferência de tecnologia envolve relações complexas e interrelacionadas entre muitas variáveis, estas relações devem impactar diretamente no modelo da transferência de tecnologia escolhida.

Para exemplificar a escolha do modelo do processo de transferência, Stock e Tatikonda (2008) utilizam uma matriz produto-processo conforme a Figura 01, combinando Incerteza Tecnológica e Interação Organizacional entre fonte e receptor. A partir destas duas variáveis, os autores listaram quatro modelos de processo de transferência de tecnologia relacionados à diagonal Incerteza-Interação, sendo cada um deles a melhor representação ou ajuste entre a variação das duas. São eles: Compra Mantendo Distância, Compra Facilitada, Mão de Obra Colaborativa e Codesenvolvimento.

A Universidade Federal da Grande Dourados UFGD) é uma organização governamental com foco na educação de nível superior. Para realizar a gestão dos seus processos internos, ela se utiliza de um conjunto de ferramentas e recursos de Tecnologia da Informação definidos no seu PDI (Plano de Desenvolvimento Institucional). Tais recursos estão disponíveis através do portal UFGDNET (UFGD, 2013a).

As instituições precisam possuir um processo onde são identificadas demandas de tecnologia latentes (HEINZL et al. 2012; KHABIRI, RAST, SENIN 2012). No caso da 
UFGD, alguns setores relataram a carência de sistemas de informação adequados à suas necessidades. Esta constatação gerou a discussão sobre a possibilidade da contratação de tecnologia externa para suprir tais demandas (UFGD, 2013 a e b).

Figura 1 A Tipologia de transferência de tecnologia interna

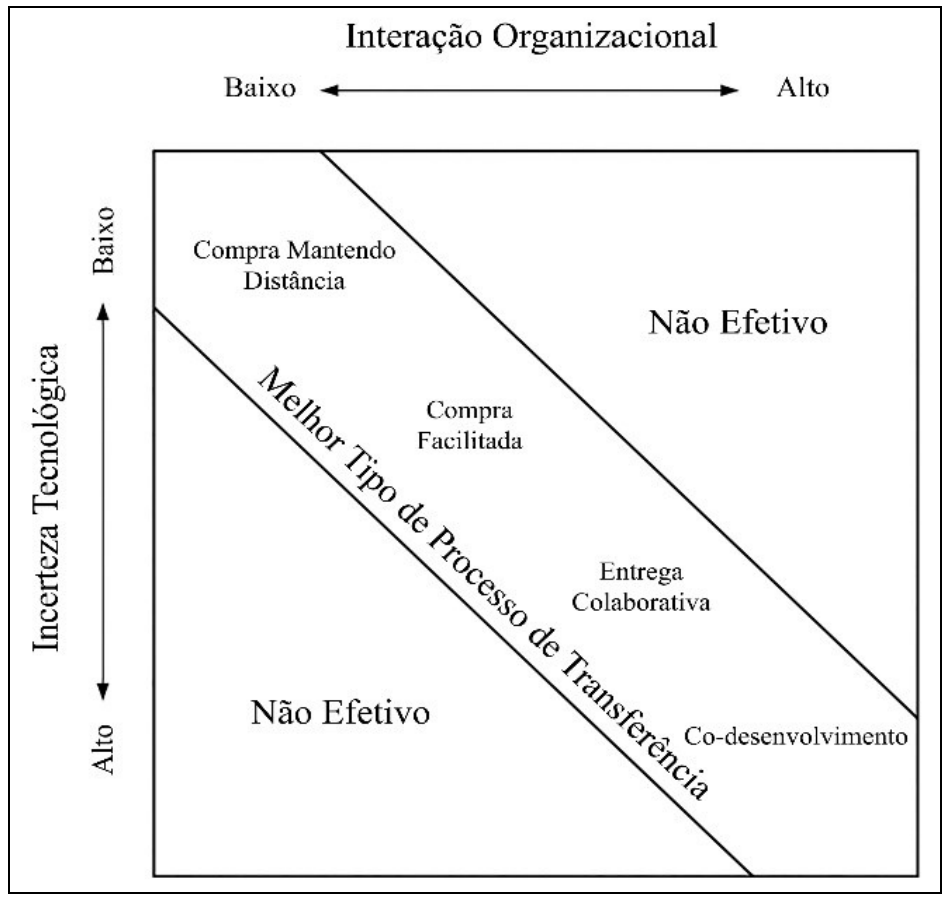

Fonte: Adaptado de Stock e Tatikonda (2000)

Após a apreciação pelo Conselho Universitário da UFGD, decide-se pela formação de uma parceria com a Universidade Federal do Rio Grande do Norte (UFRN), através de um processo de transferência de tecnologia, a UFGD passaria a receber o SIG transferido da UFRN (UFGD 2013a).

O objetivo deste estudo explorar as características da transferência de tecnologia realizada entre a UFGD e a UFRN, utilizando o modelo fornecido por Stock e Tatikonda (2000). Foram analisados os aspectos relevantes no que diz respeito à Incerteza Tecnológica e Interação Organizacional.

Em paralelo, buscou identificar qual o modelo descrito por Stock e Tatikonda (2000) que mais se encaixa na realidade da transferência de tecnologia entre as duas instituições e se as características do ambiente e da relação caracterizam uma transferência efetiva em relação ao tempo, custo e desempenho.

Ao fim, em busca de parâmetros comparativos, foram analisados os dados da UFGD com os de outras instituições que já realizaram ou ainda estão realizando o processo de 
transferência de tecnologia com a UFRN. Em posse dos resultados buscou um parâmetro do modelo de tecnologia mais comum no que diz respeito aos sistemas da UFRN e ao nível de eficácia da transferência tecnológica entre as instituições analisadas.

\section{FUNDAMENTAÇÃO TEÓRICA}

\subsection{TRANSFERÊNCIA DE TECNOLOGIA}

A transferência de tecnologia é um processo que se inicia no momento em que se identifica uma demanda latente e decide-se pela aquisição de tecnologia externa à organização. Pode-se afirmar que a conclusão do processo só se dará quando a tecnologia transferida for capaz de gerar valor no ambiente do receptor (STOCK E TATIKONDA 2008; SINGH E AGGARWAL 2010).

Assim sendo, é muito importante que o processo de transferência não seja demasiadamente demorado, oneroso, ou que ao final os resultados alcançados com a utilização da tecnologia transferida fiquem aquém do que se esperava quando se iniciou o processo de transferência (KHABIRI, RAST, SENIN 2012).

Basicamente, toda transferência de tecnologia envolve três atores: o transmissor, sendo a instituição detentora da tecnologia a ser transferida e, por consequência, a portadora de maior conhecimento sobre a mesma; o receptor, sendo este o interessado em que a transferência funcione adequadamente em seu ambiente a fim de possibilitar melhorias ou ganhos, e, por fim, a tecnologia a ser transferida, que deve ser capaz de atender ao receptor conforme suas necessidades em tempo e custo adequados (KHABIRI, RAST, SENIN 2012).

Na visão de Khabiri (2012), toda organização é dependente de tecnologia para se manter competitiva. Assim como destacado por Stock e Tatikonda (2000), não necessariamente a organização irá investir no desenvolvimento destas tecnologias e portanto busca recuso no ambiente externo. Elucidando a importância da transferência de tecnologia na manutenção da competitividade das organizações em um ambiente globalizado.

No memento que uma organização opta por realizar a transferência de tecnologia, deve realizar um estudo de viabilidade bem fundamentado a fim de medir os diversos fatores que podem impactar no processo de transferência. Caso o estudo realizado não seja eficiente, é possível que o processo enfrente problemas, resultando em uma transferência ineficaz, caracterizada por um baixo aproveitamento do material transferido, altos custos e frustração (KHABIRI, RAST, SENIN 2012). 
A condição em que se dá o processo de transferência é extremamente importante para o sucesso da mesma. No que diz respeito ao receptor, se faz necessário conhecer o ambiente a fim de determinar o que foi chamado de Incerteza Tecnológica. Sendo possível ser medida pela diferença entre o nível de conhecimento que a organização receptora possui, e aquele que seria o desejável para que se realize a transferência. A incerteza tecnológica é formada por três características básicas, descritas na Tabela 1a (STOCK E TATIKONDA, 2000).

Outra característica que impacta diretamente no processo de transferência de Tecnologia é o que Stock e Tatikonda (2000 e 2008) chamam de Interação Organizacional, tendo seus principais fatores descritos na Tabela $1 \mathrm{~b}$. Esta característica diz respeito à natureza da relação entre as organizações fonte e receptora. Fatores como a comunicação, coordenação e cooperação entre as duas organizações são a base para uma boa Interação Organizacional.

Os níveis de Iteração Organizacional e Incerteza Tecnológica se refletem na matriz produto-processo descrito por Stock e Tatikonda (2000) na Figura 01, a origem entre os dois níveis reflete o modelo de transferência de tecnologia mais adequado, sendo capaz de demonstrar possíveis falhas no processo de transferência. Para que a transferência de tecnologia seja eficaz, um mecanismo entre os disponíveis deve ser avaliado e selecionado (KHABIRI, RAST, SENIN 2012).

Como apresentado, o processo de transferência de tecnologia constitui um "projeto", os elementos-chave para que o mesmo seja considerado eficaz são: o funcionamento eficaz da tecnologia, os custos relacionados à transferência e o tempo necessário para se concluir o processo de transferência (STOCK E TATIKONDA 2000).

\subsection{ANALISANDO AS DIMENSÕES DOS MODELOS}

Antes de definir os modelos de Transferência de Tecnologia que resultam da matriz produto-processo descrito na Figura 1, é preciso entender as subdimensões que formam cada um deles Tabela 1. Na visão de Stock e Tatikonda (2000) estas subdimensões sintetizam os fatores que influenciam o processo de Transferência de Tecnologia e são os principais formadores da incerteza tecnológica e a interação organizacional. Por sua vez, são contribuintes para os requisitos e capacidade de processamento de informações entre fonte e destino. 
Tabela 1 Subdimensões de tipologia de transferência de tecnologia interna

\begin{tabular}{|c|c|c|}
\hline Subdimensão & Fatores subjacentes & Literatura representativa \\
\hline \multicolumn{3}{|c|}{ (a) Subdimensões da incerteza tecnológica } \\
\hline \multirow[t]{5}{*}{ Novidade } & Familiaridade tecnológica & $\begin{array}{l}\text { Adler, 1992; McDonough e Barczak, 1992; Yoon e } \\
\text { Lilien, 1985 }\end{array}$ \\
\hline & Novidade tecnológica & $\begin{array}{l}\text { Barnett e Clark, 1996; Tatikonda e Rosenthal, 2000b; } \\
\text { Brooks, 1987; Davidson e McFetridge, } 1985\end{array}$ \\
\hline & Inovação radical/incremental & Green et al., 1995; Ettlie et al., 1984 \\
\hline & Mudança descontinuada & $\begin{array}{l}\text { Schumpeter, 1942; Tushman e Anderson, 1986; } \\
\text { Ehrnberg e Jacobsson, } 1997\end{array}$ \\
\hline & $\begin{array}{l}\text { Inovação de } \\
\text { plataforma/derivada }\end{array}$ & Wheelwright e Clark, 1992; Tatikonda, 1999 \\
\hline \multirow[t]{3}{*}{ Complexidade } & $\begin{array}{l}\text { Interdependência do sistema } \\
\text { interno }\end{array}$ & $\begin{array}{l}\text { Singh, 1997; Khurana, 1999; Tatikonda e Rosenthal, } \\
\text { 2000b; Henderson e Clark, } 1990\end{array}$ \\
\hline & $\begin{array}{l}\text { Interdependência do sistema } \\
\text { externo }\end{array}$ & Brooks, 1987; Tushman e Rosenkopf, 1992 \\
\hline & Escopo & Clark e Fujimoto, 1991; Griffin, 1997; Shenhar, 1998 \\
\hline \multirow[t]{5}{*}{ Tacitness } & Conhecimento tácito & $\begin{array}{l}\text { Polyani, 1967; von Hippel, 1994; Howells, 1996; } \\
\text { Madhavan e Grover, } 1998\end{array}$ \\
\hline & Encarnação física & Lam, 1997; Tsang, 1997 \\
\hline & Codificação & $\begin{array}{l}\text { Kogut e Zander, 1993; Dutta e Weiss, 1997; } \\
\text { Mascitelli, } 1999\end{array}$ \\
\hline & Invisibilidade & Brooks, 1987 \\
\hline & Estrutura & $\begin{array}{l}\text { Naumann et al., 1980; Tait e Vessey, 1988; McKeen } \\
\text { et al., } 1994\end{array}$ \\
\hline \multicolumn{3}{|c|}{ (b) Subdimensões interacionais de interação } \\
\hline \multirow[t]{3}{*}{ Comunicação } & Métodos de comunicação & $\begin{array}{l}\text { De Meyer, 1991; Gibson e Smilor, 1991; Stock et al., } \\
1996\end{array}$ \\
\hline & $\begin{array}{l}\text { Magnitude e frequência de } \\
\text { comunicação }\end{array}$ & Ghoshal e Bartlett, 1988; Rebentisch e Ferretti, 1995 \\
\hline & $\begin{array}{l}\text { Natureza da informação } \\
\text { trocada }\end{array}$ & $\begin{array}{l}\text { Gibson e Smilor, 1991; Gray, 1989; von Hippel, } \\
\text { 1987; Rebentisch e Ferretti, } 1995\end{array}$ \\
\hline \multirow[t]{3}{*}{ Coordenação } & Quantidade de planejamento & Bailetti e Callahan, 1993 \\
\hline & $\begin{array}{l}\text { Formalidade e estrutura do } \\
\text { relacionamento }\end{array}$ & $\begin{array}{l}\text { Cooper, 1983; Eisenhardt e Tabrizi, 1995; Van de } \\
\text { Ven e Ferry, } 1980\end{array}$ \\
\hline & Horizonte do tempo & Adler, 1995; Rogers, 1995 \\
\hline \multirow[t]{4}{*}{ Cooperação } & Confiança & Corsten, 1987; Das e Teng, 1998; Hagedoorn, 1990 \\
\hline & $\begin{array}{l}\text { Disposição para } \\
\text { compartilhar informações }\end{array}$ & Heide e Miner, 1992; Schrader, 1991; Wong, 1999 \\
\hline & Congruência do objetivo & $\begin{array}{l}\text { Geisler, 1997; Hagedoorn, 1990; Turner et al., 1994; } \\
\text { Wong, } 1999\end{array}$ \\
\hline & Comprometimento & Geisler, 1997; Holm et al., 1996; Johnson, 1999 \\
\hline
\end{tabular}

Fonte: Adaptado de Stock e Tatikonda (2000) 


\subsubsection{Incerteza Tecnológica}

De modo geral, como descrito no texto de Stock e Tatikonda (2004), a incerteza tecnológica é a diferença entre o conhecimento requerido pela organização destinatária para adquirir e implementar a tecnologia e o nível de conhecimento que realmente possui.

Os autores sintetizam os diversos fatores que contribuem para a incerteza tecnológica em alguns fatores macro, que constituem três subdimensões essenciais da incerteza tecnológica, descritas na seção $1 \mathrm{~A}$ da Tabela 1.

- Novidade Tecnológica: refere-se ao grau de experiência anterior e o grau de mudança da tecnologia em relação às tecnologias anteriores;

- A complexidade tecnológica: inclui o nível de interdependência entre os componentes da tecnologia, o nível de interdependência entre a tecnologia e os elementos externos e o escopo tecnológico;

- A característica tácita da tecnologia: refere-se ao conhecimento particular incorporado pela tecnologia, e inclui o grau em que a tecnologia está incorporada, codificada e completa.

Stock e Tatikonda (2000) seguem enfatizando que quanto maior o nível de Incerteza Tecnológica, maior serão os requisitos de processamento das informações, podendo gerar a necessidade de adaptação no grupo de trabalho, no tempo, ou até mesmo no escopo definido. Tais adaptações podem custar tempo e dinheiro, impactando na eficácia da transferência.

Os autores destacam que cada organização possui características distintas, sendo que diferentes níveis de experiência ou capacidade de absorção podem significar, o que seja altamente incerto para uma organização não seja para outra.

\subsubsection{Interação Organizacional}

No modelo proposto por Stock e Tatikonda (2000), esta seria a segunda dimensão para os modelos de Transferência de Tecnologia, caracterizando a relação Inter Organizacional entre o transmissor e o receptor. Assim como descrito na Incerteza Tecnológica, a interação organizacional tem muitos fatores que contribuem:

- A comunicação inclui os métodos de comunicação, a magnitude, a frequência da comunicação e a natureza da informação trocada;

- A coordenação refere-se à natureza da estrutura planejada e ao processo de interações e tomada de decisão entre o transmissor e o receptor;

- Cooperação é a "vontade de um parceiro de buscar interesses mutuamente compatíveis em vez de agir oportunamente". 
Assim como acontece na Incerteza Tecnológica, níveis mais altos de interação organizacional fornecem níveis mais altos de capacidade de processamento de informações. No entanto, quando os níveis de interação organizacional são mais baixos do que o necessário, é possível que as dificuldades de comunicação e coordenação acabem se refletindo em equipes trabalhando sozinhas e realizando atividades desnecessárias ou duplicadas.

\subsubsection{Eficácia da Transferência}

A eficácia da transferência é medida por elementos chave do projeto, sendo eles:

- Tempo

- Custo

- Desempenho

Estes três elementos dizem respeito ao funcionamento adequado da tecnologia, os custos relacionados e ao tempo usado para se concluir o projeto. A eficácia é a condição desejável ao final do processo de transferência.

Na visão de Stock e Tatikonda (2000), uma combinação adequada entre Incerteza Tecnológica e Interação Organizacional resultará em uma Transferência de Tecnologia eficaz. A Figura 01, apresenta as melhores combinações entre estes dois fatores, já a Figura 02 exibe uma representação da teoria do processamento da informação organizacional aplicada à transferência de tecnologia.

Figura 2 Teoria do processamento da informação organizacional aplicada à transferência de tecnologia

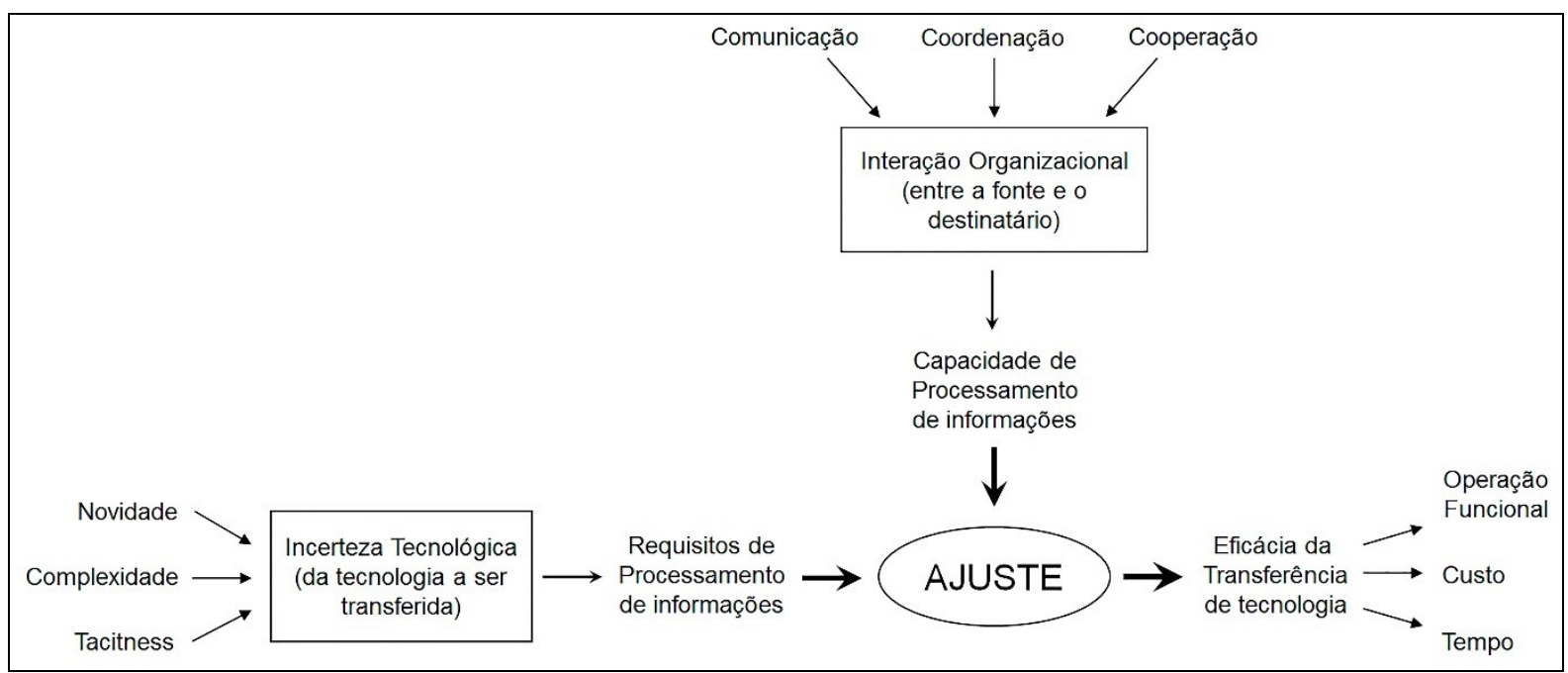

Fonte: Adaptado de Stock e Tatikonda (2004).

A eficácia na Transferência da Tecnologia deverá ser percebida pelos diversos atores envolvidos no processo, até que esta possa gerar valor aos usuários finais. 


\section{METODOLOGIA}

Como Stock e Tatikonda (2000), em seus trabalhos, não definem um método específico para o levantamento dos dados relacionados aos fatores de cada dimensão, foi utilizado nesse estudo um modelo adaptado.

A pesquisa baseou-se na metodologia transversal (BORLADO 2006), ao responder algumas perguntas pré-determinadas, os entrevistados informavam, através de uma escala Tipo Likert (HARTLEY 2013), o nível de influência que cada aspecto abordado influenciava no fator analisado. Ao final da análise de cada fator, o entrevistado atribui um peso de influência, caracterizando, assim quanto impactou diretamente na dimensão analisada.

O perfil dos entrevistados foi definido a partir da necessidade de que os mesmos possuíssem uma relação técnica direta no processo de transferência. Como ator ideal, acabouse definindo o líder da equipe técnica envolvida no recebimento. Como líder do projeto, este tem acesso à um maior volume de informações do processo de transferência, mantendo contato tanto com os profissionais da área técnica, e ao mesmo tempo mediando possíveis problemas que os usuários possam apontar na tecnologia transferida.

As instituições escolhidas para a resolução da pesquisa estão na relação de referências contidas no PDTI (Plano Diretor de Tecnologia de Informação) da UFGD, são elas:

- Universidade Federal da Bahia (UFBA),

- Universidade Federal do Ceará (UFC),

- Universidade Federal Rural do Semiárido (UFERSA),

- Universidade Federal do Maranhão (UFMA),

- Universidade Federal do Oeste do Pará (UFOPA),

- Universidade Federal do Pará (UFPA),

- Universidade Federal da Paraíba (UFPB),

- Universidade Federal do Piauí (UFPI),

- Universidade Federal Rural da Amazônia (UFRA),

- Universidade Federal do Recôncavo da Bahia (UFRB),

- Universidade Federal do Rio de Janeiro (UFRJ),

- Universidade Federal de Sergipe (UFS),

- Universidade Federal de Itajubá (UNIFEI),

- Universidade Federal da Integração Latino-Americana (UNILA)

- Universidade da Integração Internacional da Lusofonia Afro-Brasileira (UNILAB) 
Figura 3 Universidades Federais que realizaram a Adoção do SIG por região

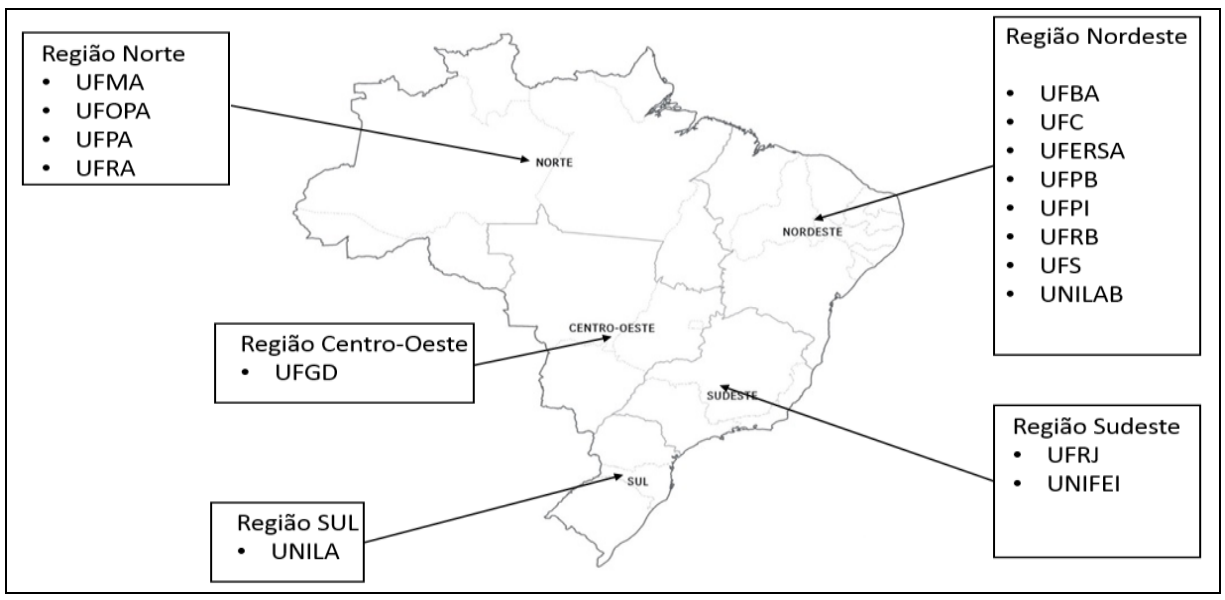

Fonte: Os autores.

Estas, foram selecionadas por serem Instituições de Nível Superior, que realizaram ou estão realizando a transferência do SIG. O Estágio da transferência varia a cada instituição analisada, sendo que algumas já concluíram o processo, porém algumas ainda estão em fazes iniciais.

A importância de se analisar o peso do fator ao final do questionário serve para medir a diferença de que cada fator representa nas várias instituições, conforme descrito em Stock e Tatikonda (2000). Esta diferença acontece pelo fato de que cada instituição possui uma realidade diferente das outras. Estas diferenças são características determinantes na definição da Incerteza Tecnológica e Interação Organizacional.

Este método foi utilizado para medir tanto a Incerteza Tecnológica, quanto a interação organizacional. Cada questão apresentada aos entrevistados seguiu um modelo definido por Stock, Tatikonda e Rosenthal (2000), quando os autores propuseram medir a dimensão da novidade tecnológica.

Figura 4 Cálculo dos Fatores da Incerteza Tecnológica e Interação Organizacional

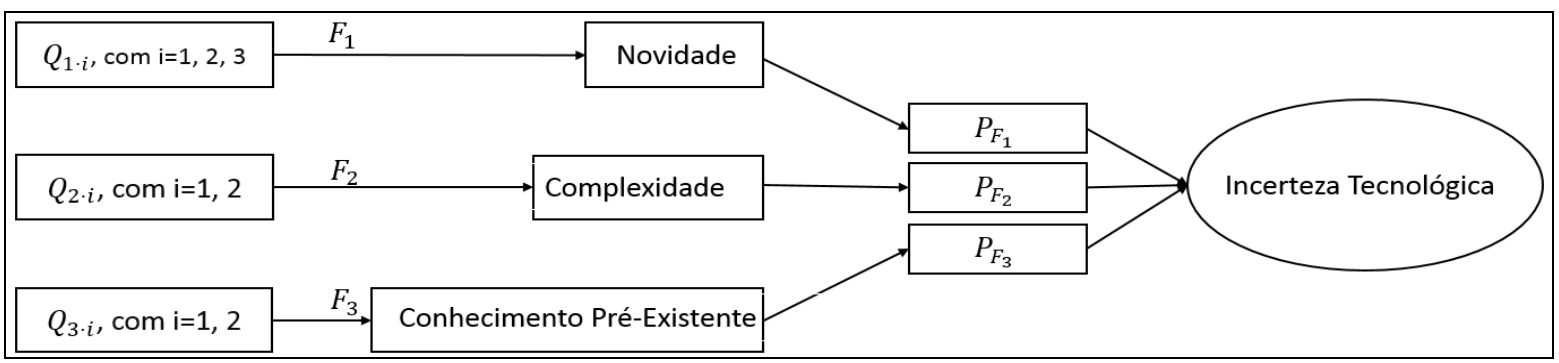

Fonte: Os Autores. 
As funções matemáticas que representam o cálculo de cada fator estão expressas na figura 05. Calculado o valor de cada fator seguindo a lógica de uma média ponderada, a somatória da multiplicação dos pesos com o valor das questões é dividida pela somatória dos pesos (MORGADO e CARVALHO, 2015).

Figura 5 Modelo Matemático usado para realizar o cálculo dos fatores analisados

$\operatorname{Dim}_{1}=\frac{P_{F_{1}}\left(v Q_{1.1}+v Q_{1.2}\right)+P_{F_{2}}\left(v Q_{2.1}+v Q_{2.2}\right)+P_{F_{3}}\left(v Q_{3.1}+v Q_{3.2}\right)}{2 P_{F_{1}}+2 F_{2}+2 P_{F_{3}}}$

Fonte: Os Autores

Para que se pudesse chegar o mais próximo do modelo de Stock e Tatikonda (2000), foi realizada uma análise das definições de cada fator descritas pelos autores, sendo assim, durante a aplicação dos questionários foram definidas algumas perguntas chaves, com o objetivo de elencar a condição de cada universidade entrevistada em relação ao fator analisado.

A partir das respostas e da análise sugerida pelo modelo matemático, foi possível obter um panorama da condição Incerteza Tecnológica nas universidades analisadas. No modelo de Stock e Tatikonda (2000), o nível de Incerteza Tecnológica impacta diretamente no nível de Interação Organizacional necessário para que ocorra um dos tipos de transferência de tecnologia descritos pelos autores.

Nesta análise, é possível verificar, baseado na opinião dos atores, os níveis de Incerteza Tecnológica e Interação Organizacional, e assim determinar se o processo de transferência utilizado foi o adequado ou não. Com os resultados, também é possível determinar se o processo de transferência terá sua eficácia comprometida, uma vez que o ponto alcançado pode determinar um maior tempo ou um maior custo na transferência caso esteja fora da diagonal definida por Stock e Tatikonda (2000) conforme Figura 01.

\section{RESULTADOS}

A pesquisa foi realizada durante um período de 09 dias entre os dias 25 de julho de 2017 à 02 de agosto de 2017, sendo que das 15 instituições selecionadas conforme PDTI, somente 09 (incluindo a UFGD) responderam ao questionário, denominadas por $\mathrm{A}, \mathrm{B}, \mathrm{C}, \mathrm{D}$, E, F, G, H, I na representação dos resultados da pesquisa. Foram utilizadas 17 perguntas de análise geral sobre o processo de transferência e 17 perguntas específicas relacionadas à incerteza Tecnológica e Interação Organizacional. 
As respostas demonstraram que os sistemas da UFRN são caracterizados por serem um produto que exige alguma expertise no processo de transferência de tecnologia. As instituições analisadas apresentaram diferentes níveis de requisitos e capacidades de processamento, e estes determinaram o modelo de transferência especifico.

Foi possível observar que $55 \%$ dos entrevistados apontam a própria UFRN como instituição que apresentou o SIG aos receptores. A adesão ao SIG só foi resultado de pesquisa interna da própria instituição em dois casos $(22 \%)$, e em outros dois casos $(22 \%)$, outras instituições apresentaram os sistemas do SIG. Isso demonstra a importância do papel do transmissor em apresentar as soluções para possíveis receptores, procurando encaixar as ferramentas de tecnologia transmitida com as demandas institucionais.

Após a apresentação da tecnologia aos receptores, é necessário um incentivador ao processo de Transferência. No caso dos entrevistados, as instituições tiveram como maiores incentivadores os órgãos superiores da administração, tais como Reitoria em conjunto com o setor de Tecnologia de Informação (TI). Esta realidade se repete na UFGD, a administração observou as demandas de diversos setores da instituição, dando início ao processo de recebimento dos sistemas da UFRN.

No que diz respeito aos prazos, as instituições estimaram em média, 04 anos (levando em consideração as datas de início e conclusão apontadas pelos entrevistados) para que se realizasse o processo de transferência, sendo que 44,4\% afirmaram já o ter concluído. Deste grupo, algumas relatam ainda realizar atividades do processo de transferência, o que caracteriza a existência de adaptações ao fluxo dos processos ou no próprio sistema.

Foi possível observar que $55,6 \%$ das instituições ainda não finalizou o processo de transferência e, do total, apenas uma pequena minoria $22,2 \%$, não realizou mudanças no prazo inicial de conclusão do projeto. As adaptações no cronograma de transferência geralmente resultam em maior custo para instituição receptora e, na maioria das vezes, são reflexo da Incerteza Tecnológica. Apesar disto, nenhuma instituição se mostrou interessada em abandonar o processo de transferência de tecnologia, e até mesmo aquelas que já possuem os sistemas em produção, não têm interesse em adquirir outro tipo de solução de software para substituir o SIG, isso demonstra que mesmo com as dificuldades no cumprimento dos prazos e os gastos, as instituições consideram a transferência eficaz.

Nos dados analisados, ficou claro que todo o processo de recebimento da tecnologia é realizado pelo setor de TI da instituição, realidade que se repete em todas as instituições 
analisadas, fator importante pois a incerteza tecnológica engloba também os usuários que irão gerenciar a ferramenta, estes pertencentes aos mais diversos setores da instituição, normalmente não possuem conhecimento sobre a ferramenta, gerando demandas de adaptação do sistema ou do fluxo de processos da instituição, as alterações normalmente demandam tempo e impactam tanto na efetiva utilização do sistema quanto no custo final do processo, comprometendo a eficácia do mesmo.

Em relação a contração de mão de obra terceirizada, 55,5\% das instituições relataram a necessidade para realizar o processo de recebimento da tecnologia. Conforme Khabiri (2012), um estudo de viabilidade é capaz de preparar a instituição para a contratação e fundamentar os investimentos realizados.

Como resultado $44,4 \%$ afirmam ter realizado o processo de transferência somente com os recursos disponíveis, sem a contratação de terceiros. Indicando que apesar de existirem instituições que necessitam de ajuda externa para realizarem o projeto de transferência, existem as que possuem o volume de mão de obra necessária e são capazes de coordenar as ações internas ao mesmo tempo em que realizam a transferência.

No que diz respeito a interação dos usuários com os sistemas do SIG, 66,7\% afirmaram ter um feedback positivo, e é possível que ocorra por algumas instituições não possuírem sistemas de TI para tratarem seus fluxos de processo. Com a adesão ao SIG, mesmo sendo necessárias algumas adaptações, as instituições passaram a possuir as ferramentas adequadas para dar continuidade às suas atividades.

Tais adaptações causaram descontentamento aos usuários nas primeiras fases do processo de implantação, porém, com o tempo, o fluxo de trabalho torna-se mais natural. Ao mesmo tempo, ao disporem de ferramentas que, até o processo de transferência, não existiam ou não funcionavam adequadamente, os usuários se tornam mais produtivos, melhorando o produto do trabalho. Sendo assim, as ferramentas incorporadas pelo processo de Transferência do SIG são capazes de gerar valor às instituições receptoras, este valor se apresenta através da diminuição de tempo e recursos na execução das tarefas, satisfação dos servidores com as ferramentas de trabalho e do feedback positivo por parte dos clientes.

Os entrevistados apontaram como maiores dificultadores do processo de transferência, a falta de maturidade das equipes receptoras, destacando, em sua maioria, a falta de familiaridade com o fluxo dos processos definidos pelo novo sistema. A adaptação à esta condição levou tempo, causando atraso no cronograma definido previamente. 
Como agentes facilitadores, os entrevistados apontaram suas próprias equipes de implantação que, após o período de adaptação e consolidação, conseguiram dar continuidade ao processo de transferência de forma satisfatória. Outro agente facilitador apontado foi a UFRN, que prestou o suporte necessário.

\subsection{INCERTEZA TECNOLÓGICA E INTERAÇÃO ORGANIZACIONAL}

Durante a aplicação do questionário perguntas foram direcionadas com o objetivo de levantar dados sobre a Incerteza Tecnológica e Interação Organizacional, conforme o modelo definido por Stock e Tatikonda (2000).

O processamento das informações gerou a Figura 06, onde pode-se visualizar o posicionamento das instituições analisadas dentro do modelo proposto pelos autores.

Figura 6 Resultado da Pesquisa realizada nas instituições pesquisadas.

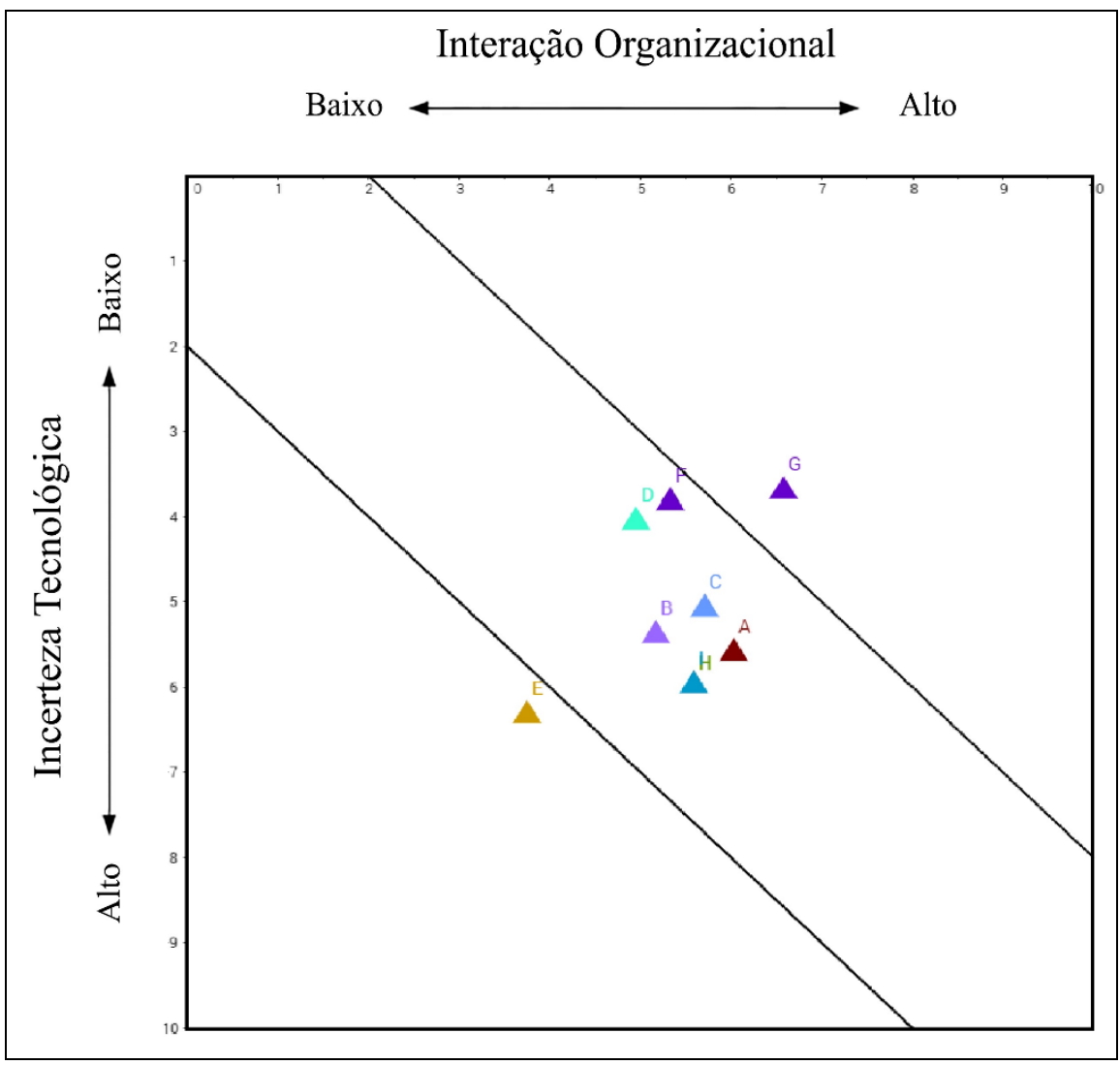

Fonte: Os Autores

Na Figura 07 é possível ver o resultado em comparação com o modelo definido por Stock e Tatikonda (2000). 
As 4 tipologias principais que caracterizam o processo de Transferência de Tecnologia, compra mantendo distância, compra facilitada, entrega colaborativa e codesenvolvimento, na Figura 06, a maioria das instituições se mantem entre a Compra Facilitada e a Entrega Compartilhada, significando que tais instituições possuem um bom ajuste entre a Incerteza Tecnológica e a Interação Organizacional, sendo que a maioria ficou dentro do limite definido por Stock e Tatikonda (2000) caracterizando uma transferência de Tecnologia Efetiva, sendo justificada pela pesquisa, quando relatado ter um feedback positivo quanto à utilização da tecnologia transferida.

Figura 07 Modelo de Stock e Tatikonda comparado com o resultado das instituições Pesquisadas

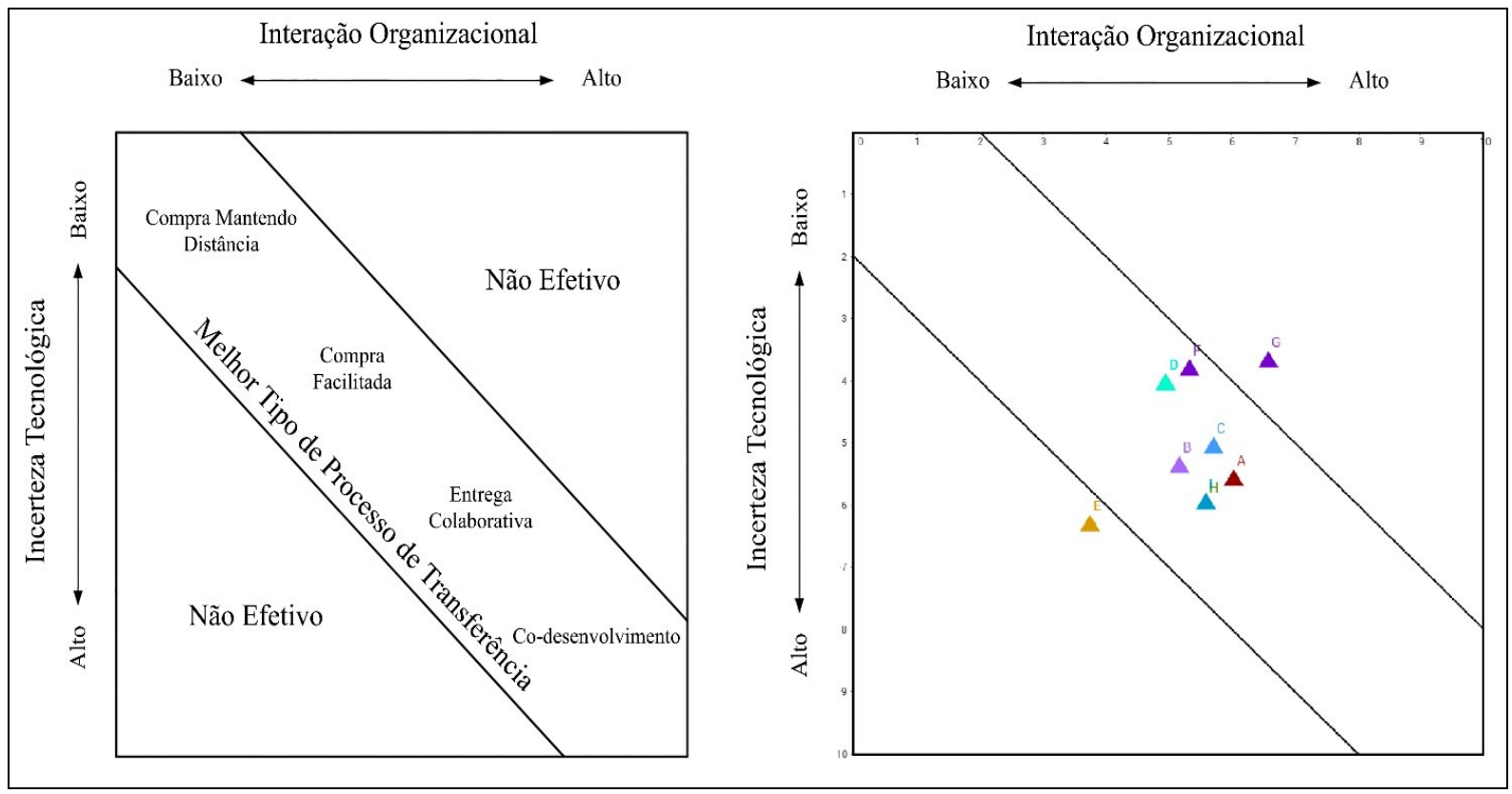

Fonte: Os autores

No entanto duas instituições ficaram fora da diagonal de efetividade, sendo que uma delas demonstrou ter um nível de Incerteza Tecnológica bastante alto em relação à sua Interação Organizacional. Este tipo de condição demonstra que a transferência provavelmente levou, ou levará mais tempo do que o estimado inicialmente, também serão necessários investimentos em pessoal e treinamento, além do fortalecimento dos sistemas de comunicação e coordenação com a UFRN, fator determinante para que se possa ajustar o processo de transferência dentro da diagonal de efetividade, proposto pelos autores Stock e Tatikonda (2000). 
A outra instituição que aparece fora da diagonal de efetividade demonstra ter um nível de Incerteza Tecnológica pequeno, e uma Interação Organizacional alta. Esta condição é favorável ao processo de transferência, segundo Stock e Tatikonda (2000), resulta em um processo efetivo e rápido, porém caracteriza-se por um processo demasiadamente caro, provavelmente existe uma força de trabalho superdimensionada e os recursos altamente dimensionados para realidade da instituição. Esta condição é caracterizada como não efetiva porque o processo de transferência de tecnologia custa mais caro do que o valor gerado pelo produto.

Quanto ao modelo de Transferência de Tecnologia adotado, 3 instituições (D, F e G) ficaram mais próximos da chamada Compra Facilitada, que se caracteriza pela organização transmissora fornecendo informações e orientações para o destinatário na utilização da tecnologia. Neste modelo, existe um maior nível de comunicação, onde são repassadas informações não triviais, relacionadas ao funcionamento e implantação da tecnologia.

Outras 06 Instituições (A, B, C, E, I e H) apresentaram dados que caracterizam uma Entrega Colaborativa, existindo uma maior incerteza sobre os dados transmitidos e como serão repassados ao receptor. Este modelo exige ações efetivas de comunicação e cooperação e exige uma maior atenção nas ações de coordenação, bem como nos requisitos e capacidade de processamento.

A UFGD (Figura 06 - Letra D, Azul) ficou localizada no grupo de instituições que realiza uma Compra Facilitada dos sistemas da UFRN. Conforme apontado anteriormente, neste modelo, existe um maior nível de comunicação, onde são repassadas informações não triviais, relacionadas ao funcionamento e implantação da tecnologia.

\section{CONCLUSÃO}

O modelo de pesquisa adotado serviu para identificar o tipo de Transferência de Tecnologia que as instituições utilizaram, são capazes de determinar o quanto as instituições devem investir para que se adaptem aos requisitos e capacidades de processamento. No caso da pesquisa, ficou claro que as instituições estão seguindo as especificações presentes no modelo de Compra Facilitada e Entrega Colaborativa, conforme definido por Stock e Tatikonda (2000).

Uma informação relevante no caso da UFGD se refere às adaptações que já foram realizadas no cronograma e na equipe de implantação. $\mathrm{Na}$ pesquisa sobre a Incerteza 
Tecnológica e Interação Organizacional, a instituição se mostrou capaz de realizar uma Compra Facilitada, porém quando questionada a respeito do cronograma e da equipe responsável pela implantação, o entrevistado afirmou ter realizado alterações em ambas.

Indicando que a partir das adaptações, a instituição possui os requisitos necessários para a implantação, porém quando analisado o processo desde o início, fíca evidente que a adaptação no cronograma e as mudanças na equipe já causam resultam em maior custo do que o definido no início do projeto, este custo adicional poderá impactar na eficácia do projeto quando finalizado.

Conforme a pesquisa destacou, a UFGD tem as condições necessárias para realizar uma Compra Facilitada do SIG, porém o projeto deverá respeitar o cronograma e manter as especificações relativas a Incerteza Tecnológica e Interação Organizacional.

A pesquisa foi realizada em um grupo de entrevistados que possuem um perfil especifico de interação com o projeto de Transferência de Tecnologia. Como sugestão de novos trabalhos, se faz necessária uma pesquisa mais abrangente, com responsáveis pelo recebimento, bem como com os usuários finais do sistema, afim de perceber a opinião destes com relação aos fatores analisados neste trabalho. No caso do SIG, a interação dos usuários com o sistema impacta diretamente no valor do produto final.

Outro fator a ser analisado em estudos mais abrangentes é a percepção do cliente final quanto ao valor gerado após a utilização do SIG. A Instituição de Ensino deverá prestar um melhor trabalho após a implantação dos sistemas da UFRN, e deve ser percebido pela comunidade acadêmica como um todo.

Em linhas gerais, o estudo identificou os fatores que devem ser levados em consideração quando se realiza o processo de Transferência de Tecnologia do SIG a partir da UFRN, sendo capaz de identificar as instituições que realizaram mudanças desde o início do processo como um todo e apontar, através da diagonal de efetividade do modelo definido anteriormente, que estas instituições estão seguindo os parâmetros para uma transferência de tecnologia efetiva. Houve instituições que se mostraram fora dos parâmetros definidos no modelo, porém isto pode corrigido através de investimento e adaptações.

Ao final do estudo, foi possível identificar o modelo de Transferência de Tecnologia utilizado na UFGD, sendo este o mais próximo da Compra Facilitada. Algo que ficou evidente, foi as alterações no cronograma e realização de mudanças na equipe responsável pelo processo de Transferência. Estas alterações já impactam no nível de Incerteza 
Tecnológica e Interação Organizacional e, em conjunto, possibilitam condições para que a UFGD realize uma Transferência de Tecnologia eficaz, desde que os fatores analisados na pesquisa não sofram alterações durante o processo de transferência.

\section{REFERÊNCIAS}

BORDALO, A.A. Estudo transversal e/ou longitudinal. Rev. Para. Med., Belém, v.20, n.4, dez, 2006.

HEINZL, J. KOR, A, L. ORANGE, G. KAUFMANN, H, R. Technology transfer model for Austrian higher education institutions 607 - 640, 2012.

KHABIRI, N. RAST, S. SENIN, A, A. Identifying Main Influential Elements in Technology Transfer Process: A Conceptual Model $417-423$

MONDRAGON H, N. D, P; DOMÍNGUEZ, D, P; FLORES, R, S, A. Conceptual Model of Technology Transfer for Public Universities in Mexico 24 - 35, 2013.

MORGADO, A.C.O., CARVALHO, P.C.P., Matemática Discreta, Coleção PROFMAT, SBM, 2013.

PDI/UFGD - Plano de Desenvolvimento Institucional - 2013-2017. Dourados: UFGD, 2013b. Disponível em: < http://files.ufgd.edu.br/arquivos/arquivos/78/ADMINISTRACAOUFGD/PDI\%20UFGD\%202013 2017.pdf >Acesso em 08 jun. 2017.

SINGH, A, AGGARWAL, G. Technology Transfer Introduction, Facts and Models. International Journal Of Pharma World Research, 1(2), 1-8.2010.

STOCK, G., N; TATIKONDA, M. V. External technology integration in product and process development 642-665, 2004.

STOCK, G., N; TATIKONDA, M. V A typology of project-level technology transfer processes. Journal of Operations Management, Vol.18(6), pp.719-737, 2000.

TATIKONDA, M.V., ROSENTHAL, S. R., Successful execution of product development projects: balancing firmness and flexibility in product innovation. Journal of Operations Management 18 (4), 401-425, 2000a.

TATIKONDA, M.V., ROSENTHAL, S. R., Technology novelty, project complexity and product development project execution success: a deeper look at task uncertainty in product innovation. IEEE Transactions on Engineering Management 47 (1), 74-87, $2000 \mathrm{~b}$.

TATIKONDA, M.V., STOCK, G.N. The joint influence of technology uncertainty and interorganizational interaction on external technology integration success, 66-78, 2008. 
TATIKONDA, M.V., STOCK, G.N., Product technology transfer in the upstream supply chain. Journal of Product Innovation Management 20 (5), 444-467, 2003.

UFGD - UNIVERSIDADE FEDERAL DA GRANDE DOURADOS. Plano Diretor de Tecnologia da Informação - PDTI/UFGD 2014-2017. Dourados: UFGD, 2013a. Disponível em: $<$ http://files.ufgd.edu.br/arquivos/arquivos/78/COUNI/res\%20195 2013\%20anexo\%20\%20PDTI-.pdf $>$ Acesso em: 08 jun. 2017. 